\title{
Interpretações do Brasil
}

Sergio Barreira de Faria Tavolaro (https://orcid.org/0000-0003-2755-3361), Departamento de Sociologia, Instituto de Ciências Sociais, Universidade de Brasília, Brasília, Distrito Federal, Brasil'.

Resumo: Ao revisitar algumas das mais prestigiadas obras de interpretação do Brasil, o artigo debruça-se sobre o sentimento de descompasso que permeia os retratos da vida social brasileira ali delineados. A conjectura que se quer examinar é que, admitida a pluralidade de perspectivas que colorem essa fatura, tais obras insinuam primar no país um ordenamento temporal intricado e sinuoso, apenas em parte sincronizado ao tempo homogêneo, progressivo e linear dos contextos modernos modelares. Importa-me, ademais, contemplar um conjunto de formulações críticas ao imaginário sociológico com o propósito de explorar uma segunda hipótese: tão logo apreciados em diálogo com essas proposições críticas, retratos da sociedade brasileira esboçados nessas obras parecem dispor de elementos sugestivos de um enquadramento teórico sensível às incongruências, assimetrias e tensões que atravessam a temporalidade moderna. Ao final do artigo, pretendo refletir sobre o alcance heurístico dessas ideias e suas eventuais contribuições para o debate sociológico contemporâneo.

Palavras-chave: Pensamento brasileiro. Modernidade no Brasil. Teoria sociológica. Interpretações do Brasil. Modernidade.

\section{Interpretations of Brazil and the temporality of modernity: towards an epistemological critique}

Abstract: While revisiting some of the most acclaimed oeuvres of the so-called Brazilian social thought, the article examines the feeling of temporal mismatch that underlies a wide variety of portraits of social life in Brazil. I contend that notwithstanding the variegated analytical perspectives inherent to this intellectual constellation, most of these oeuvres are inclined to ascribe to Brazil a peculiar temporal configuration, only partially synchronized with the homogeneous and linear-progressive time envisaged in modernity. That said, I am also interested in investigating a set of critical propositions to the sociological imagination in order to assess an additional hypothesis, namely: these very same visions of Brazilian society seem to insinuate an alternative theoretical frame of reference, sensitive to the unbalances, asymmetries and contradictions that crisscross modernity's temporality. In the end, I reflect upon the heuristic potential of such ideas and their contributions to contemporary sociology.

Keywords: Brazilian social thought. Modernity in Brazil. Sociological theory. Interpretations of Brazil. Modernity.

\author{
* Este artigo é \\ fruto dos projetos \\ de pesquisa \\ 204704/2018-9 e \\ 303189/2019-3 \\ (CNPq). Agradeço às/ \\ aos pareceristas da \\ revista Sociedade e \\ Estado pelas valiosas \\ sugestões, as quais \\ me auxiliaram \\ a aprimorar o \\ argumento do \\ trabalho.
I. Sergio Tavolaro é professor do Departamento de Sociologia e do Programa de Pós-Graduação em Sociologia da Universidade de Brasília. Bolsista pesquisador do CNPq. Doutor em sociologia pela The Research, New York, NY, Estados Unidos. <sergiotavolaro@ hotmail.com>. \\ New School for Social
}




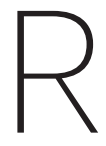

etratos da vida social brasileira delineados em algumas das mais celebradas obras de interpretação do Brasil tenderam a referir-se a esta como uma experiência destoante de contextos em regra associados às gêneses e à dianteira da modernidade. Trata-se, com efeito, de um fato amplamente constatado pela fortuna crítica. A julgar por aqueles trabalhos, razões não faltariam para tal condição díspar: os efeitos sociais de um meio natural singular, as heranças culturais dos colonizadores, a composição racial e os padrões comportamentais de suas gentes, a dispersão populacional do vasto território, os costumes e as instituições sedimentados ao longo de sua existência, suas estruturas econômicas incongruentes, a posição periférica e dependente do país no cenário mundial, dentre outros, combinados ou não entre si, foram apenas alguns dos aspectos inquiridos com o propósito de desvelar a realidade nacional e discernir seus predicados distintivos. Por si só, tamanha profusão de ideias é reveladora da enorme multiplicidade de abordagens que conforma esse pensamento. Admitidos os incontáveis desacordos dessas formulações, suas convergências são igualmente indisfarçáveis. Afora o fato de partilharem uma mesma preocupação primordial - leia-se, perscrutar as alegadas circunstâncias especiais de nossa formação -, suas afinidades estendem-se a ao menos outra seara, a saber: a percepção desta como uma sociedade que, além de ter ingressado tardiamente na modernidade, manteve-se descompassada das principais referências e parâmetros modernos.

Nas páginas que se seguem, retomarei esses retratos à luz de um aspecto do discurso da modernidade que ocupa lugar de destaque na sociologia. Como bem se sabe, nos termos desse imaginário, o advento da era moderna fez-se acompanhar da instauração de uma configuração temporal sem precedentes (Morfino \& Thomas, 2018; Rosa, 2013). Em conformidade com as novas instituições e padrões de sociabilidade então estabelecidos, tal temporalidade seria marcadamente abstrata e uniforme, apoiada sobre o desenrolar progressivo e linear do tempo (Anderson, 1991; Gumbrecht, 2015). No presente artigo, almejo examinar alguns dos alicerces epistemológicos daquele sentimento de descompasso orientado por duas conjecturas articuladas. Conforme a primeira delas, apesar da pluralidade de perspectivas que colorem o pensamento brasileiro, essas ideações convergem ao indicarem a existência de um ordenamento temporal no Brasil irredutível aos contextos modelares da modernidade. Nesse caso, condizente com suas formas societárias especiais, prevaleceria no país uma temporalidade truncada e heterogênea, coabitada por vivências e sentidos diversos do tempo. Aturdida por toda sorte de desacordos (econômicos, políticos, institucionais, culturais, ético-morais, cognitivos etc.), abundariam as evidências de se tratar de uma sociedade dissonante na cena moderna. 
É certo que, ao ratificar nossa condição extemporânea e reflexa na contemporaneidade, esse diagnóstico difuso concorre para confirmar o vigor epistemológico daquela temporalidade hegemônica ${ }^{1}$. Atento a tais convergências, importa-me em igual medida revisitar proposições críticas ao imaginário sociológico, ciosas de facetas da vida social comumente subapreciadas pelo cânone. A segunda conjectura que pretendo apurar é que apreciadas em diálogo com essas formulações críticas, imagens da sociedade brasileira inscritas em obras-chave de interpretação do país dispõem de elementos sugestivos de um enquadramento teórico alternativo, sensível às incongruências, assimetrias e tensões que perpassam a experiência do tempo na modernidade. Ao final do artigo, pretendo ponderar acerca do alcance heurístico dessas ideias e de suas eventuais contribuições para o debate sociológico atual.

\section{Interpretações do Brasil e o sentimento de descompasso}

Sobressai-se na produção sociológica a ideia conforme a qual a emergência da modernidade constituiu uma ruptura histórica com repercussões sociais definitivas (Marx, 1990; Weber, 2002; Durkheim, 1997). De acordo com essa concepção, as instituições e os padrões de sociabilidade então inaugurados ergueram-se apoiados em um novo sentido do tempo (Habermas, 1990; Luhmann, 1976): alheia aos movimentos e vicissitudes do mundo natural, a temporalidade moderna mostrar-se-ia cada vez mais vazia e abstrata, resguardada de influências socioculturais localizadas (Anderson, 1991: 24; Giddens, 1991: 25-29; Zerubavel, 1982 2-3). Sua orientação irresistivelmente progressiva evidenciaria a predileção dessa experiência pela mudança em detrimento da permanência e da tradição (Morfino \& Thomas, 2018: 1-2; Gumbrecht, 2015; Habermas, 1990; Harvey, 1995; Koselleck, 2006; Rosa, 2013)². Associado quase sempre a transformações históricas inerentes à Europa e ao Ocidente (Anderson, 1991; Giddens, 1991), esse novo enquadramento do tempo acabaria por aspirar elevar-se à condição de referência universal, sobrepondo-se a percepções, vivências e conotações alternativas (Koselleck, 2006: 284-285; Zerubavel, 1982) . $^{3}$

Como quero argumentar, esses parâmetros epistemológicos são igualmente caros a um repertório variado de obras e formulações do pensamento brasileiro. Decerto, tendo sido engendrados em contextos sócio-históricos diversos e em circunstâncias políticas e intelectuais bastante diferentes, são profusas as discordâncias - analíticas e político-normativas - entre tais esforços de interpretação do país. Instiga-
1. Vale lembrar, Maria Sylvia Carvalho Franco (1976: 63) já afirmava que "as teorias sobre a história brasileira são sustentadas por uma temporalidade entendida como série causal, estabelecendo-se entre os polos que se articulam no capitalismo mundial uma relação linear de condição à consequência."

2. Esse enquadramento aproxima-se daquilo que Hans Gumbrecht (2015: 14-15) denomina de cronótopo do "pensamento/ consciência histórica", cujos traços principais seriam os seguintes: i. "a humanidade [...] se imagina num percurso linear, movimentando-se no tempo";

ii. presume-se que

"todos os fenômenos são influenciados pela mudança no tempo";

iii. acredita-se que, com o transcorrer do tempo, as "experiências passadas" perdem relevância

"enquanto pontos de orientação" iv. concebe-se "o futuro [...] como horizonte aberto de possibilidades em direção ao qual a humanidade vai construindo o seu caminho"; v. o "presente" torna-se uma experiência efêmera, 
comprimido entre "o futuro e o passado"; vi. no centro dessa construção situa-se o "sujeito cartesiano", ao qual se atribui capacidade para agir e efetuar "escolhas".

3. Com referência

a "um tempo cronologicamente idêntico", diferentes configurações sociais passaram, então, a ser tipificadas sob o signo da "simultaneidade do não simultâneo" (Koselleck, 2006: 284-286).

\section{A título de} ilustração, cabe recordar que, embora partícipes de uma mesma geração, não eram poucas as divergências entre as visões de Euclides da Cunha, Manoel Bomfim e Paulo Prado a respeito das fontes das especificidades do Brasil. Em certa medida, algo similar pode ser dito a propósito de Freyre, Buarque de Holanda e Prado Jr., cujas obras são com frequência apontadas como matrizes interpretativas díspares da vida social brasileira.

5. Elide Bastos sustenta que "a grande indagação presente nos vários momentos de desenvolvimento do pensamento social brasileiro diz respeito à questão do atraso" (Bastos, 2013: 288). Glaucia Villas-Bôas, por sua vez, referese à "flagrante das por preocupações prementes a cada época e amparadas em enquadramentos teóricos e variáveis explicativas inconfundíveis, as agendas de pesquisa perseguidas por inúmeras gerações e coortes de pensadores mostraram-se muitas vezes incompatíveis (Brandão, 2007; Botelho \& Schwarcz, 2009; Cardoso, 2013) 4 . Seja como for, contabilizadas suas singularidades, prevalece nesse universo intricado de representações a propensão compartilhada para se referir a esta como uma experiência social apenas em parte sincronizada à temporalidade e aos padrões societários modernos (Bastos, 2013; Lage, 2016; Lima, 2013; Villas-Bôas, 2003) 5 . Embora não descarte a relevância e profundidade de seus desacordos ${ }^{6}$, interessa-me prioritariamente explorar as convergências que subjazem essas imagens, empenhado em analisar suas contiguidades e clivagens com relação àquele discurso sociológico hegemônico ${ }^{7}$.

Certa feita, Maria Sylvia de Carvalho Franco (1976: 61) aludiu a uma "formulação" que Ihe parecia "inscrita em pelo menos dois séculos de nossa história intelectual" - qual seja, a tendência para retratar "a metrópole [como] o centro produtor das relações socioeconômicas e a colônia como seu produto". Segundo a autora, ao instituir "uma relação de exterioridade entre os dois termos em oposição" - dispostos, desse modo, numa "ordem de sucessão" - esse registro interpretativo supõe ser "pela ação expansionista dos centros adiantados que se operam as mudanças substanciais nos países atrasados" (Carvalho Franco, 1976: 61, grifos no original). Transcorridas várias décadas desde seu delineamento, a meu ver essa proposição continua a oferecer uma senda de leitura profícua do pensamento brasileiro. É digno de nota que, na segunda metade do século XIX, referindo-se à incompletude da formação nacional, Silvio Romero chamasse atenção para nossa suscetibilidade aos "modelos" e "formas do pensamento cultural" originários "da Europa e dos Estados-Unidos" (Romero, 1949: 87 e 296). Pouco antes, em seu consagrado libelo antiescravagista, Joaquim Nabuco (2000: 113) já havia se reportado à "decadência prematura" do país, aferrado a uma "porção retardatária do globo" e indiferente às referências morais e legais vigentes nas "sociedades civilizadas" (Nabuco, 2000: 79). Desalento análogo é recorrente no épico Os sertões, em especial nas lucubrações de Euclides da Cunha acerca da fortuna dos sertanejos ante os avanços iminentes da civilização: "Retardatários hoje", vaticinava o autor, "amanhã se extinguirão de todo" (Cunha, 2016: 10). À mesma época, conquanto se mostrasse um crítico contundente do tom "condenatório" e dos estereótipos racistas que se projetavam sobre o Brasil e demais sociedades latino-americanas, Manoel Bomfim (1993: 43, 50 e 238-267) não se eximia de recorrer à imagem do "atraso" para retratar a região. A seu ver, a despeito de "relacionados diretamente, intimamente a todos os outros povos cultos", os países do subcontinente permaneciam presos "num estado que mal lhes dá o direito a ser considerados povos civilizados" (Bom- 
fim, 1993: 49-50). Apesar de também declinar de atribuir os problemas enfrentados pela sociedade brasileira aos alegados vícios e imperfeições de suas raças formadoras, Alberto Torres continuava a nutrir aquele mesmo sentimento de decalagem vis-à-vis as "velhas sociedades e civilizações" (Torres, 1978: 19): padeceríamos da falta "de espírito nacional 'prático', da solidariedade patriótica fundada na consciência dos interesses comuns a todos os agrupamentos políticos, religiosos, econômicos, geográficos, comerciais e industriais" (Torres, 1978: 85). Daí a premência de se "construir artificialmente a nacionalidade", sem o que "países novos" como o Brasil jamais conseguiriam chegar "à idade da vida dinâmica" (Torres, 1978: 43). Ao menos nesse aspecto, o diagnóstico de Oliveira Vianna não poderia distar mais das proposições de seu mestre. Em seu entendimento, o quadro "antropológico e racial" brasileiro representava um verdadeiro "caos étnico" (Vianna, 1956: 137), efeito do cruzamento "de três raças distintíssimas" (Vianna, 1956: 123), duas das quais, segundo ele, inaptas aos padrões de uma vida plenamente civilizada. A essas dificuldades se somariam outras, de cunho político e institucional, resultado do vazio demográfico "na imensidão imensurável da terra" (Vianna, 1956: 199). De todo modo, suas formulações tornavam a reiterar a percepção de uma sociedade que, sob o impacto de "fatores étnicos", aliados a "fatores econômicos, fatores geográficos, fatores históricos, fatores climáticos" especiais, seguia um itinerário inconfundível (Vianna, 1956: 29-30) ${ }^{8}$.

Bem se sabe que a efervescência cultural da década de 1920 acabaria por descreditar várias dessas ideias. Nas hostes modernistas, guardadas as particularidades de cada plataforma, os Manifestos Pau-brasil, Antropófago e Verde-amarelo trataram de enaltecer a formação étnico-racial brasileira, ao tempo em que também valorizaram a autenticidade e a riqueza de nossas realizações culturais. Em reação ao hábito arraigado da importação de ideias pelas "elites vegetais", oferecia-se o antídoto da poesia e da literatura nacionais, urdidas em intensa conversação "com o solo" (Andrade, 2017b: 54) ${ }^{9}$. Ainda assim, ao exaltarem a alegada aptidão do país para conciliar elementos oriundos de épocas e lugares diversos - sintetizando de maneira criativa elementos arcaicos e modernos, complexos e rudimentares ${ }^{10}$-, tais retratos furtivamente contribuíram para reforçar a imagem de uma experiência apenas em parte alinhada à modernidade, de resto, reafirmada como padrão de medida da cadência nacional ${ }^{11}$. É sugestivo, aliás, que Paulo Prado, ele próprio um incentivador da Semana de 1922, tenha se servido profusamente de noções "passadistas" para elaborar seu Retrato do Brasil. Por suas mãos, raça e natureza retomaram o protagonismo de outrora, ao que se adicionavam a "ambição do ouro" (a "cobiça") e a "sensualidade livre e infrene" (a "luxúria") - segundo ele, os "dois grandes impulsos" da aventura colonizadora (Prado, 2012: 39). Ao final, não deveria estranhar que mesmo 300 anos após a chegada dos portugueses à América, o oposição" de certas visões do Brasil "às obras que se baseiam nas concepções modernas e progressistas de tempo" (Villas-Bôas, 2003: 120-121). Veja se, também, Victor Lage (2016: 76).

6. É lícito afirmar que tamanha diversidade de preocupações, de abordagens teóricas e de programas de reflexão traduziu-se na conformação de

"famílias intelectuais" e "linhagens de pensamento" distintas - ou seja, numa pluralidade de "formas de pensar extraordinariamente persistentes no tempo" (Brandão, 2007: 29). Nesse caso, seria possível referir-se à existência "de uma 'linhagem liberal' (Rui Barbosa) de uma 'perspectiva conservadora' (Visconde do Uruguai), de uma 'abordagem patriarcalista' (Freyre), de uma 'perspectiva patrimonialista' (Faoro), de uma 'nacionaldesenvolvimentista' (Guerreiro Ramos), [de] uma 'periféricodependentista' (Celso Furtado), dentre outras. Essas várias modalidades de interpretação retrataram, cada qual a seu modo (ainda que não necessariamente de maneiras excludentes), as continuidades e rupturas entre o Brasil e outros contextos" (Tavolaro, 2014: 641). 
7. Na mesma trilha seguida por Carvalho Franco (1976: 61), parece-me subsistir no pensamento brasileiro um conjunto de supostos amplamente partilhados, os quais concorrem para acercar os horizontes de cognição de distintas gerações e coortes de intérpretes a respeito da identidade e do estatuto do Brasil na quadra moderna.

\section{Na avaliação de Vianna (1956: 40), "somos diversos por muitos aspectos, distintos por muitos lados, peculiares e exclusivamente nós mesmos por muitos modos de ser e de existir."}

9 Assim também exortava o Manifesto Antropófago (1928):

"Contra todos os importadores de consciência enlatada." (Andrade, 2017b: 51) Por sua vez, o Manifesto verde-amarelo afirmava que "estávamos e estamos fartos da Europa, e proclamamos sem cessar a liberdade de ação brasileira" (mimeo).

10. Dizia o seguinte o Manifesto da poesia pau-brasil (1924):

"A saudade dos pajés e os campos de aviação militar" (Andrade, 2017a: 27).

11. Donde adviria o imperativo de "Acertar o relógio império da literatura país continuasse "um corpo amorfo, de mera vida vegetativa, mantendo-se apenas pelos laços tênues da língua e do culto" (Prado, 2012: 110). Vítima de um passado que insistia em prolongar-se no presente, a vida nacional parecia-lhe manter-se assolada na "indigência intelectual e artística completa, em atraso secular, reflexo apagado da decadência da mãe-pátria" (Prado, 2012: 110-111).

Aspectos caros a essas visões perderiam vigor no correr da década de 1930 sob a liderança de uma nova geração de pensadores. Ao conceber a cultura africana como alavanca civilizadora do país, Casa-Grande \& Senzala ambicionava desafiar variáveis explicativas que pareciam a Freyre perturbar a compreensão adequada da formação brasileira. Destarte, passava-se a reputar esta como "a primeira sociedade moderna [...] nos trópicos com características nacionais e qualidades de permanência" (Freyre, 2000: 86). O teste maior dessa experiência, examinado em seus pormenores em Sobrados e Mucambos, se faria sentir no curso do século XIX. A partir daquele momento, a sociedade sofreria o impacto de forças padronizadoras diversas, compelindo-a a ajustar-se às instituições, aos valores e ao ritmo frenético da Europa industrial. De todo modo, na visão do intérprete, certo núcleo identitário próprio, refratário aos avanços niveladores da modernidade, lograva subsistir, desacelerando a cadência moderna e fazendo-a alcançar desigualmente os estratos sociais e as distintas regiões do território (Freyre, 1936). Ao menos nesse ponto, as convergências com o diagnóstico traçado em Raízes do Brasil são notórias: também para Sérgio Buarque de Holanda, o século XIX representou o desembarque em terras brasileiras de ideias e padrões societários erigidos na Europa moderna. Tal a magnitude das transformações que, à certa altura, "uma revolução lenta, mas segura e concertada" ganhou corpo, de modo a acarretar "o advento de um novo estado de coisas" (Holanda, 1936: 135-136). Não obstante, para o autor, essas alterações de modo algum redundariam na adesão integral e sem suturas da sociedade às referências normativas e aos valores modernos. Isso porque, em seu entendimento, embora já estivéssemos assistindo o "aniquilamento das raízes ibéricas de nossa cultura" (Holanda, 1936: 137), persistiria entre nós "um mundo de essências mais íntimas", segundo Holanda, "sempre intacto, irredutível e desdenhoso das invenções humanas" (Holanda, 1936: 160-161).

Por aqueles anos, Caio Prado Jr. burilava uma interpretação alternativa, com ênfase nas circunstâncias e móveis econômicos que, desde o final do século XV, orientaram a aventura portuguesa na América. Prado Jr. salienta que, ao contrário das zonas temperadas e setentrionais do "novo continente", povoadas na esteira de conflitos religiosos e políticos do Velho Mundo, as regiões tropicais e subtropicais abriram "aos países da Europa a possibilidade da obtenção de gêneros" de que careciam (Prado Jr., 2011: 25). Empreendimento com "acentuado caráter mercantil", 
estaria aí "o verdadeiro sentido da colonização tropical, de que o Brasil" constituíra um de seus desdobramentos (Prado Jr., 2011: 28). Na conhecida avaliação do autor, esse começo especial viria a inscrever-se "profunda e totalmente nas feições e na vida do país" (Prado Jr., 2011: 29), de forma a determinar suas instituições políticas, sociais e econômicas, além de prefigurar com afinco seu escopo de possibilidades. Disso resultou um itinerário histórico inconfundível com as sociedades metropolitanas, apesar de a elas vinculado de maneira visceral. Tal a tenacidade desse legado que, a seu ver, mesmo nos dias de hoje, "uma viagem pelo Brasil é muitas vezes, [...] uma incursão pela história de um século e mais para trás" (Prado Jr., 2011: 11).

Não restam dúvidas que os processos de institucionalização e profissionalização da prática científica no país fizeram-se acompanhar de novas noções e abordagens analíticas a respeito da realidade nacional. É sintomático, pois, que Celso Furtado concebesse seu próprio esforço de interpretação da formação econômica brasileira em contraste com "o fatalismo supersticioso das teorias de inferioridade de clima e 'raça' [...]" (Furtado, 2009: 164). Nada disso, contudo, o demovia de também vislumbrar o Brasil como uma experiência defasada em relação aos centros dinâmicos do capitalismo mundial, propensa a "transformar-se no século XX numa vasta região subdesenvolvida [...]" (Furtado, 2009: 64). Aqui, como em outras passagens da obra, é nítida a percepção de se tratar de uma sociedade constrangida pelo peso do passado, impedida de comandar autonomamente o seu devir. Importante frisar, à mesma época, a despeito de mobilizado por uma agenda de reflexão distinta a saber, a "persistência secular da estrutura patrimonial" no Brasil - sentimento análogo subjaz a íntegra do mais conhecido trabalho de Raymundo Faoro (2001: 822). O zelo com que se dedica à história portuguesa decorria justamente da convicção de que a condição presente do país fora selada há tempos, quando Portugal inaugurou uma rota peculiar em direção à modernidade. Naquelas circunstâncias, sustenta Faoro, prenunciou-se um ordenamento político incompatível com os preceitos do liberalismo europeu, avesso às instituições democráticas e ao progresso industrial da nação. No fim das contas, o quadro brasileiro demonstrava o preço a pagar pela conciliação entre o tradicional e o moderno: uma modernização retardatária e aquém das realizações do mundo anglo-saxão (Faoro, 2001: 822-823 e 831-832).

As alegadas especificidades da modernização nacional são igualmente foco das atenções de Alberto Guerreiro Ramos. Cioso das discrepâncias econômicas, sociais e políticas que nos afastavam dos "países líderes" do mundo ocidental e que toIhiam nossa "autodeterminação", a sociedade brasileira parecia-Ihe um caso exemplar de "contemporaneidade do não coetâneo'", palco de "todas [as fases] pelas nacional", missão atribuída às "gerações futuristas" (Manifesto da poesia pau-brasil, Oswald de Andrade, 2017a: grifos meus). 
quais a humanidade até agora já passou, desde o comunismo primitivo ao capitalismo de Estado" (Guerreiro Ramos, 1996: 64 e 139-140). Percepção semelhante é partilhada por Luiz de Aguiar Costa Pinto, para quem seria possível discernir no Brasil, a um só tempo, "dois padrões de estratificação social - o tradicional e o novo" (Costa Pinto, 1973: 248). Nesse cenário invulgar, "classes residuais, típicas da sociedade arcaica do passado" conviveriam "ao lado de classes emergentes, resultantes do desenvolvimento e partes integrantes da sociedade que está sendo construída no presente" (Costa Pinto, 1973: 248). Tratar-se-ia, em sua avaliação, de uma condição típica de configurações "desigualmente desenvolvidas", caracterizadas pela simultaneidade de "padrões de organização social" contraditórios e de estratos sociais concernentes "a diferentes épocas de sua evolução estrutural" (Costa Pinto, 1973: 248).

Parte importante dessas ideias converge com diagnósticos lavrados por Florestan Fernandes. Note-se que, ao inquirir a respeito dos contornos do "capitalismo dependente" brasileiro, a "articulação de estruturas econômicas heterogêneas no sistema econômico nacional" volta a ser realçada pelo autor (Fernandes, 2008: 60-61). Também nesse caso, ao invés de "secundária e suplementar", a "combinação [dessas formas] com outras, mais ou menos modernas e até ultramodernas" (Fernandes, 2008: 61) constituiria um traço essencial de contextos capitalistas periféricos. Dessa feita, restava-Ihe evidente que, em contraste com as experiências centrais, nas margens do sistema, "a expansão da economia interna" jamais chegava a suprimir integralmente padrões produtivos arcaicos (Fernandes, 2008: 63). Por esse motivo, quando do advento do "capitalismo monopolista" no país, em lugar da completa eliminação de estruturas passadas, a sociedade brasileira viu aprofundar-se, em seu próprio seio, "a distância existente entre várias épocas histórico-econômicas distintas (mas coetâneas)" (Fernandes, 2006: 313).

Apoiados em supostos e variáveis explicativas nem sempre coincidentes - composição racial, meio físico, instituições políticas, herança cultural, economia, posição geopolítica, dentre outras -, as especificidades de cada um desses retratos do Brasil são iniludíveis. Ainda assim, subsiste de maneira abrangente a percepção desta como uma vida social apenas em parte alinhada aos parâmetros predominantes nos ditos cenários modernos modelares - isto é, a referências cognitivas e preceitos ético-morais, a configurações institucionais e expectativas comportamentais, a arcabouços culturais e estruturas econômicas entrevistos na modernidade. À modernização tardia e vacilante da sociedade brasileira corresponderia um arranjo temporal incongruente, truncado e descontínuo. Isso posto, importa indagar se a incidência habitual e pertinaz de elementos do passado no presente - dentre outros motivos, em virtude da resiliência de visões de mundo, valores, instituições e padrões pro- 
dutivos oriundos de circunstâncias e momentos históricos outros -, combinada à sensação de incerteza com relação ao devir são aspectos exclusivos aos assim chamados contextos periféricos, sinal de seu desencaixe na modernidade.

\section{Imagens contra-hegemônicas da temporalidade moderna}

É preciso haver-se com dois conjuntos de ideias diretamente implicados nessas imagens da experiência social. Para começar, o enquadramento abstrato, homogêneo, progressivo e linear do tempo, com frequência assumido como exemplar da modernidade, aparece no mais das vezes atrelado a um padrão de sociabilidade tomado igualmente por paradigmático da vida moderna. Na imaginação sociológica, tal padrão é em geral codificado a partir de cinco pilares principais: diferenciação social, racionalização moral e cognitiva, disjunção público/privado, subjetivação e separação cultura/natureza (Rosa, 2013: 58; Tavolaro, 2008: 275; 2014: 644-645) ) $^{12}$. Em segundo lugar, de acordo com esse mesmo discurso sociológico, tanto as gêneses daquele enquadramento temporal hegemônico quanto o advento desse padrão societário específico são, com igual regularidade, vinculados de maneira primordial à história interna e a predicados culturais, epistemológicos, políticos, institucionais, econômicos etc. atribuídos à Europa e ao Ocidente, de onde teriam em seguida se disseminado para outras regiões do globo (Anderson, 1991: 36; Giddens, 1991: 173-174). Escapa aos propósitos do artigo revisitar a intricada história da ascensão e triunfo dessa autocompreensão moderna, tantas vezes examinada pela fortuna crítica (Gumbrecht, 1998; Habermas, 1990; Koselleck, 2006). Importa-me tão somente explorar, no próprio seio do pensamento sociológico, o potencial analítico de outras referências e noções, indicativas dos limites dessa concepção dominante - a começar pela linhagem intelectual que une Marx, Bloch e Althusser ${ }^{13}$.

As famigeradas proposições de Marx a respeito do "anacronismo" social alemão apontam, já de partida, para as insuficiências da compreensão homogênea e linear do tempo. A julgar por suas reflexões, no século XIX, a Alemanha via-se aturdida por toda sorte de tensões, atravessada por uma diversidade desconcertante de temporalidades (Marx, 1970: 141). No plano político, a barafunda de elementos do passado que teimavam em precipitar-se no presente levava Marx a vislumbrar o país como "um fato empoeirado no quarto de despejo (junkroom) histórico das nações modernas" (Marx, 1970: 132). Algo análogo parecia-Ihe suceder na esfera econômica, nitidamente aquém do desenvolvimento alcançado pelas sociedades avançadas da Europa. De todo modo, malgrado as ineludíveis assincronias históricas de sua vida social, no plano intelectual os alemães mostravam-se "contemporâneos do presente", engajados nas mesmas "questões" que mobilizavam a porção
12. Conforme esse imaginário, quanto mais resguardados dos imperativos do mundo natural, quanto mais circunscritos seus âmbitos públicos e privados de ação, quanto mais ancorados em agentes dotados de vida subjetiva centrada, quanto mais internamente diferenciados e racionalizados, e, por fim, quanto mais abstrata e homogênea sua concepção do tempo mais modernos se mostrariam os contextos sociais considerados (Tavolaro, 2017: 122).

13. Para uma cuidadosa análise das formulações desses autores em torno da noção de "não contemporaneidade", ver Vittorio Morfino (2018) e Morfino \& Thomas (2018). Acompanho algumas das sugestões ali delineadas. 
adiantada do continente (Marx, 1970: 135-136). No fim das contas, não só pelo fato de encarnar as imperfeições do Estado moderno, mas também por partilhar com as nações avançadas "as dores desse desenvolvimento", a sociedade alemã revelava-se útil à compreensão do presente europeu (Marx, 1970: 139).

Os alegados descompassos da Alemanha acabariam retomados nas reflexões de Ernst Bloch acerca dos desafios que se apresentavam ao país na década de 1930. Bloch (1977) aludia a um quadro de estratificação social bastante complexo, assentado sobre uma variedade perturbadora de épocas históricas. Para começar, em seu entendimento, os camponeses continuavam a viver "quase exatamente como seus antepassados", aferrados ao "ciclo de uma natureza inalterada" e confinados a padrões de "tempos pré-capitalistas" (Bloch, 1977: 24-25). À direita do espectro político, a juventude de origens burguesas alheava-se cada vez mais do presente na expectativa de reencontrar-se em um futuro que se the anunciava promissor. Por sua vez, as classes médias urbanas pareciam a Bloch ter optado "ficar para trás", movidas pelo desejo de "retornar às condições do pré-guerra" e, desse modo, reviver os melhores momentos de outrora (Bloch, 1977: 25-26). Por essas e outras razões, a Alemanha se Ihe indicava "a terra clássica do não sincronismo, isto é, dos resquícios não superados de existência e consciência econômicas mais antigas" (Bloch, 1977: 29-30). Importa ressaltar que, na avaliação do autor, nada disso obstava o país de compartir da cena mundial presente e de abrigar em suas hostes segmentos e classes sociais que, conquanto defasados no tempo, "pertenc[iam] completamente ao hoje" (Bloch, 1977: 27). Daí porque, embora antagonismos envolvendo elementos sincrônicos e não sincrônicos de épocas passadas continuassem a tensionar a sociedade alemã - tanto objetiva quanto subjetivamente -, a contradição fundamental do capitalismo contemporâneo - aquela entre o proletariado e o capital monopolista - não deixava de se fazer atuante no país (Bloch, 1977: 33-34).

Preocupações afins encontrariam em Louis Althusser um encaminhamento teórico auspicioso. Bem se sabe que ao debruçar-se sobre o "tempo histórico hegeliano" interessava-Ihe examinar duas ideias basilares: de um lado, o sentido do tempo como uma "continuidade homogênea"; e, de outro, a noção de "contemporaneidade do tempo", ou seja, a ideia de um "presente histórico" capaz de delimitar os horizontes de possibilidade da "totalidade social" (Althusser, 1970: 94-95). Segundo Althusser, visto que na abordagem hegeliana "todos os elementos do todo sempre coexistem em um mesmo tempo, em um mesmo presente, e são, desse modo, contemporâneos entre si e com o mesmo presente" (Althusser, 1970: 94), qualquer esforço bem-sucedido de superação da compreensão homogênea, contínua e contemporânea do tempo histórico requeria a crítica da noção de "totalidade social". 
Sob a influência de Marx, a solução delineada pelo autor avançava no sentido de realçar a existência de "níveis ou instâncias" variadas do social (o econômico, o político, o ideológico, o estético, o teórico, o religioso etc.), concebidos como partes de um "todo estruturado". O ponto crucial para Althusser era que, a despeito de "coexistirem no interior dessa unidade estrutural complexa", tais instâncias conservavam-se "relativamente autônomas", articulando-se umas às outras somente a partir de "determinações específicas" (Althusser, 1970: 97).

Importa salientar que, em virtude dessa condição, cada um desses níveis sociais disporia de "um tempo peculiar", de uma história "pontuada por ritmos peculiares" - conforme nos dá a entender Althusser, com rupturas, contiguidades, subversões, cadências e encadeamentos próprios -, os quais apenas chegariam a "ser conhecidos sob a condição" de se estipular "o conceito da especificidade de sua temporalidade histórica" (Althusser, 1970: 99-100, grifos no original). Vale dizer, em hipótese alguma qualquer um desses planos conseguiria alcançar autonomia plena uma vez que, na visão do autor, suas particularidades estariam sempre "baseadas em relações diferenciais entre os diferentes níveis dentro do todo" (Althusser, 1970: 99-100). Seja como for, Althusser afastava por completo a existência de um "mesmo tempo histórico" (Althusser, 1970: 104, grifos no original), presumidamente contínuo e homogêneo, capaz de nivelar e/ou de fazer coincidir todas as instâncias sociais num mesmo presente. Ademais, na ausência de um "tempo idêntico, único", tampouco poder-se-ia cifrar as "diferentes temporalidades" do social "como o atraso, avanço, sobrevivência ou desenvolvimento desigual [...] desse tempo" (Althusser, 1970: 106).

A seu modo, as análises de Marx, Bloch e Althusser tornam evidentes as precariedades daquela concepção vazia e uniforme, progressiva e linear da temporalidade moderna. De suas reflexões insinua-se um enquadramento alternativo: uma configuração densa e intricada, contraditória e assimétrica, coabitada por uma multiplicidade de ritmos e sentidos do tempo. Interessa-me o fato de que tais proposições também nos convidam a redimensionar o estatuto modelar que um conjunto específico de itinerários históricos e padrões de sociabilidade particulares ocupam no imaginário sociológico da modernidade.

Itinerários sociais na modernidade:

outras perspectivas de análise

Conforme observado, distintas obras do pensamento brasileiro, elaboradas numa variedade de circunstâncias históricas e contextos políticos e culturais, tenderam a conceber o país como uma experiência erguida sobre parâmetros societários des- 
14. Veja-se a nota 2 acima. compassados de cenários modernos modelares. Computada a miríade de abordagens e agendas de reflexão que perfazem esse universo intelectual, há todavia um conjunto específico de ideias bastante difuso e contumaz: alude-se, primeiramente, a uma sociedade apenas em parte diferenciada, marcada pela sobreposição de esferas sociais (política, economia, sociedade civil, família, cultura etc.) e de suas correspondentes responsabilidades; argumenta-se, em segundo lugar, que conquanto à certa altura tenha sido afetado por processos de racionalização próprios à modernidade, o tecido social brasileiro e suas principais instituições mantiveram-se suscetíveis à influência de concepções de mundo mágico-religiosas e de regras de conduta tradicionais; tratar-se-ia, ademais, de uma vida social conformada por instâncias privadas de convivência e por seus respectivos códigos de sociabilidade; por fim, seria esta uma experiência notadamente impactada pelas inconstâncias e movimentos do mundo natural (Tavolaro, 2014: 642-644; 2017: 125-128). Engendrados nos marcos epistemológicos do cronótopo da "consciência histórica" (Gumbrecht, 2015: 14-15) ${ }^{14}$, não surpreende que esses retratos instiguem um forte sentimento de decalagem temporal: respaldadas por uma conotação progressiva, linear e homogênea do tempo - cujas gêneses são no mais das vezes associadas a trajetórias históricas tidas por originárias da modernidade -, tais imagens soem codificar as instituições e padrões societários brasileiros sob o signo do "atraso".

Em décadas recentes, impulsionados por uma ampla gama de programas de pesquisa, abundaram os desafios desferidos aos pressupostos dessas ideações. Desde a "incredulidade" pós-moderna aos "metarrelatos" (Lyotard, 2013: XVI), as críticas às narrativas convencionais da modernização só fizeram avolumar-se. Servindo-se da noção de modernidades múltiplas, Shmuel Eisenstadt dirige duras objeções às promessas de "que o programa cultural da modernidade tal como ele se desenvolveu na Europa moderna e as constelações institucionais básicas que lá emergiram em última instância predominariam em todas as sociedades" (Eisenstadt, 2000: 1). Somados à importância conferida às "antinomias internas e contradições" próprias aos cenários modelares, o autor alega que os "padrões Ocidentais" de modo algum poderiam ser considerados "as únicas modernidades 'autênticas'”, a despeito de seu pioneirismo histórico e de constituírem "um ponto de referência básico para outras" (Eisenstadt, 2000: 2-3 e 7). Trata-se, com efeito, de um diagnóstico contíguo a algumas das proposições em torno da modernidade global: apesar de, também aqui, precedência cronológica seja atribuída à Europa, argumenta-se que mudanças qualitativas fundamentais ocorreram à medida que os parâmetros europeus alcançaram outras regiões do Ocidente sob a liderança norte-americana (Schmidt, 2012: 4) Mais recentemente, teríamos testemunhado a emergência de "uma pluralidade de centros [...] ao redor do globo, gerando inovações com significado potencialmente mundial, e/ou servindo como modelos de referência para imitação 
em qualquer lugar no mundo" (Schmidt, 2012: 5). Por essa razão, a sociologia contemporânea ver-se-ia cada vez mais compelida a rever suas noções e seus postulados europeus e ocidentais em favor de uma "perspectiva global" propriamente dita (Schmidt, 2012: 7).

Críticas a esse imaginário desfechadas pelas agendas decolonial e pós-colonial assumem tonalidades ainda mais contundentes. À sua maneira, ambos os programas empreendem exercícios sistemáticos de desconstrução e análise da geopolítica do conhecimento e dos supostos historicistas diretamente implicados nas autorrepresentações modernas ${ }^{15}$. Ao discorrer sobre o triunfalismo subjacente a certo discurso hegemônico, Enrique Dussel examina duas concepções antagônicas da modernidade. De um lado, um entendimento "eurocêntrico, provinciano, regional", que a retrata precipuamente como "uma 'saída' da imaturidade por um esforço da razão como processo crítico". Produto de mudanças endógenas à história europeia, "o Renascimento Italiano, a Reforma e a Ilustração alemãs e a Revolução Francesa" seriam seus eventos cruciais (Dussel, 2005: 60-61). De acordo com o autor, sob o pretexto de sua (autoproclamada) superioridade, tal enquadramento atribuiu-se à missão de "desenvolver os mais primitivos, bárbaros, rudes, como exigência moral", de moldá-los à sua semelhança, aceitando como "inevitáveis os sofrimentos ou sacrifícios (os custos) da 'modernização' dos outros povos 'atrasados' (imaturos)" (Dussel, 2005: 64-65). Haveria, no entanto, uma compreensão alternativa, ciosa das assimetrias de poder e dos processos de apagamento do "Outro" que desde sempre acompanharam essa experiência. Nesse caso, 1492 converte-se no ponto de inflexão por excelência, momento a partir do qual "todo o planeta se torna o 'lugar' de 'uma só história mundial' [...]" (Dussel, 2005: 61). Por esse novo olhar, a par com o avanço da Razão, o "mundo colonial e o usufruto da vida de suas vítimas" passam a ser considerados corresponsáveis pelas criações modernas (Dussel, 2005: 63 e $66)^{16}$. Destarte, ao invés de estranhos ao projeto emancipatório da razão, violência e coerção (física, sexual, simbólica, psicológica, epistemológica etc.) constituiriam suas condições latentes de possibilidade. Seria precisamente essa "a 'outra face' oculta e essencial à 'Modernidade': o mundo periférico colonial, o índio sacrificado, o negro escravizado, a mulher oprimida, a criança e a cultura popular alienadas etc. [...]" (Dussel, 2005: 65).

Preocupação similar com as determinações geopolíticas e os efeitos epistemológicos das relações imperialistas do Ocidente com seus "Outros" perpassa as lucubrações de abordagens pós-coloniais. Em seu esforço de "provincianização figurativa da Europa" à luz de contextos societários subalternizados, Dipesh Chakrabarty investe contra o que denomina de "historicismo" - segundo ele, "um modo de pensar" ancorado em certa "ideologia do progresso" (Chakrabarty, 2000: 7). Nos
15. Do que se segue a preocupação de ambos com as epistemologias e experiências "subalternas/ coloniais", distorcidas, quando não inteiramente invisibilizadas pelas narrativas hegemônicas da modernidade.

16. Segundo o autor, já àquela altura começaram a ganhar corpo instituições e padrões societários que posteriormente viriam a ser vinculados de maneira estrita à Europa - dentre elas "a subjetividade constituinte, a propriedade privada, a liberdade contratual etc." (Dussel, 2005: 61). 
17. Segundo o autor, "[...] na própria Europa, [o historicismo] tornou possível histórias completamente internalistas da Europa", retratada "como o primeiro local da ocorrência do capitalismo, da modernidade ou do Iluminismo." (Chakrabarty, 2000: 7).

18. Uma abordagem esclarecedora acerca dos limites e das possibilidades dos diálogos entre a "reflexão pós-colonial" e a teoria sociológica com vistas à "desprovincianização da sociologia" pode ser encontrada em Sérgio Costa (2006: 129-131). termos dessa episteme, ao lado do lluminismo, o capitalismo e a modernidade costumam ser apresentados como fenômenos inerentemente europeus, disseminados para outras localidades do mundo através de processos sucedidos "ao longo do

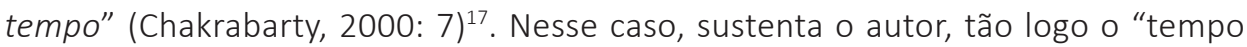
histórico" converteu-se em "medida da distância cultural [...] entre o Ocidente e o não Ocidente", as colônias e suas respectivas populações foram deslocadas para "um 'outro' lugar na estrutura temporal" (Chakrabarty, 2000: 7-8). Isso ajudaria a explicar a inépcia desse "pensamento político e social" dominante para acomodar, em suas categorias e conceitos convencionais, modalidades alternativas de agência e de ontologia (Chakrabarty, 2000: 9 e 16). Ocorre que, em vez de sinais inequívocos de atraso na modernidade, tais disparates parecem a Chakrabarty comportar um potencial para interpelar criticamente os "pressupostos ontológicos envolvidos nas concepções seculares do político e do social" - e, não menos importante, para desafiar a própria "natureza do tempo histórico" (Chakrabarty, 2000: 15-16). Em última instância, a se considerar a dinâmica política da maior parte das experiências contemporâneas, muito se perderia em codificar como "arcaicas e atrasadas" todas as formas de sociabilidade resistentes ao "tempo homogêneo e vazio" (Chatterjee, 2008: 60 e 62). De outro modo, melhor seria conceber esse "espaço real da vida moderna" à maneira de "uma heterotopia", ou seja, como um quadro "heterogêneo, desigualmente denso" (Chatterjee, 2008: 62) ${ }^{18}$.

Foge aos objetivos do artigo perscrutar, em seus pormenores, cada uma dessas agendas de reflexão. Almejo apenas ressaltar afinidades expressivas de seu desalento com as ambições cognitivas de certo discurso hegemônico da modernidade. Para começar, em lugar de simétricos, englobantes e lineares, tais proposições chamam atenção para o teor fragmentário, contingente e oscilante dos processos de modernização. Adicione-se a isso as recorrentes objeções ao estatuto modelar do Atlântico Norte, em particular às expectativas de que os parâmetros ético-morais, as configurações institucionais (políticas, econômicas e culturais), as referências cognitivas e o ordenamento jurídico entrevistos nesse contexto seriam integralmente emulados em outras partes do globo. Ato contínuo, destaca-se o dinamismo e a criatividade com que as ditas experiências "tardias" lograram adaptar tais parâmetros, configurações e referências às circunstâncias alegadamente especiais de sua formação. Demais, são nítidas as preocupações com as assimetrias epistemológicas inerentes a esse imaginário bem como com sua propensão para relegar a segundo plano ou mesmo ignorar por completo concepções de mundo e padrões de sociabilidade alternativos. Por fim, em contraste com suas inclinações internalistas - isto é, a tendência desse ideário para irrogar o advento da modernidade e suas transformações substantivas a fatores endógenos aos itinerários europeus e norte-americanos -, prefere-se relevar as conexões e os intercâmbios diversos 
(culturais, econômicos, políticos, epistemológicos, militares, institucionais, ético-morais etc.) que participaram da construção da vida moderna em diferentes momentos da história ${ }^{19}$.

\section{Interpretações do Brasil e o tempo da modernidade: aportes teóricos}

Mesmo quando se tem em conta suas realizações mais aclamadas, prevalece a avaliação de que o escopo de relevância de obras de interpretação do Brasil - ou, se assim se preferir, sua capacidade para elucidar aspectos da experiência social contemporânea amplamente considerada - é por demais restrito. O principal motivo de tal limitação estaria no fato de se tratar de ideias concernentes a um cenário tardio e periférico, a uma sociedade somente em parte sincronizada aos parâmetros e às instituições da modernidade (Tavolaro, 2017). Ocorre que, conforme acima sublinhado, os pressupostos historicistas dessa apreciação tornaram-se foco crescente de objeções. Não apenas dissolveram-se, já há algumas décadas, as promessas de que as ditas experiências "centrais" poderiam vir a ser referências inequívocas aos contextos "tardios" (e.g., Cardoso \& Faletto, 2004: 27-52). Em última instância, as próprias fronteiras que outrora os separavam - como se constituíssem cenários substancialmente distintos, irredutíveis em seus traços essenciais - parecem elas mesmas diluir-se a passos largos (Hall, 2011: 108-110).

Essas controvérsias suscitam uma série de reflexões a propósito das conotações da categoria tempo que informam o pensamento sociológico. Há pouco observei que adensaram-se as críticas às insuficiências daquele enquadramento abstrato, homogêneo e linear do tempo em face à enorme complexidade, às assimetrias e às contradições que desde sempre participaram da dinâmica moderna. A se considerar, pois, "os ritmos diferentes, os entrelaçamentos, as rupturas e descontinuidades" dessa experiência, ao invés de um "tempo único" ou "fundamental", melhor parece falar-se de uma "pluralidade de temporalidades" (Morfino \& Thomas, 2015: 18) vale frisar, "temporalidades mistas e frequentemente 'discordantes'" (Harootunian, 2007: 474) ${ }^{20}$. Mas há algo mais nessas análises. Trata-se de dizer que transformações recentes se encarregaram de tornar ainda mais explícitas as precariedades de tal concepção hegemônica. Nos dizeres de Gumbrecht (2015), estaríamos diante da emergência de um novo arranjo temporal, caracterizado pela "justaposição de diferentes tempos históricos" (Gumbrecht, 2015: 52): enquanto, por um lado, "os passados" continuam a proporcionar "pontos de orientação" ao presente, de molde a saturá-lo com suas "memórias" e "objetos" (Gumbrecht, 2015: 16 e 104); por outro, "o futuro" deixou de desenhar-se "como horizonte aberto de possibilidades" para fazer-se "uma dimensão cada vez mais fechada a quaisquer prognósticos" (Gum-
19. Uma vez mais, cabe reforçar que, no caso dos decoloniais e póscoloniais, é nítido o realce às coerções (epistemológicas, simbólicas, físicas, morais, sexuais, psicológicas etc.) inerentes aos entrelaçamentos entre as sociedades hegemônicas e os contextos societários periféricos/coloniais (Chakrabarty, 2000; Dussel, 2005).

20. Para Harootunian (2007: 486),

a "mistura de temporalidades" no presente histórico, ou ainda, "a articulação dessas misturas ambíguas do moderno e arcaico, novo e velho, aqui e lá, contemporâneo e nativista sempre esteve presente para nos lembrar da perseverança de uma refração temporal notabilizada pela contemporaneidade do não contemporâneo" (Harootunian, 2007: 475). 
21. Victor Lage divisa em vários ensaios produzidos no seio do pensamento brasileiro não apenas "uma problematização mais ampla das linhas de demarcação que separam e unificam o dentro e o fora, o passado, o presente e o futuro" do país (Lage, 2016: 572), mas também o potencial para "expor um processo global" (Lage, 2016: 559). Nesse sentido, tais obras constituiriam "Iugares potenciais de crítica da modernização" (Lage, 2016: 36) ao inquirem "conceitos centrais daquilo que é comumente definido como 'modernidade' [...]" (Lage, 2016: 533).

22. Aludindo aqui a uma proposição de Roberto Schwarz, tal movimento de "desprovincianização" implicaria em "inscrever na atualidade internacional, em forma polêmica, muito daquilo que parecia nos afastar dela e nos confinar na irrelevância" (Schwarz, 1998: 13). brecht (2015 15). No fim das contas, avultariam os contornos de um "amplo presente, com seus mundos simultâneos" - ou seja, de um "presente [que] transformou-se numa dimensão de simultaneidades que se expandem" e se deslocam "em direção ao futuro e ao passado" (Gumbrecht, 2015: 16). Ora, não é difícil depreender as implicações desses debates para o pensamento sociológico: cientes do alcance descritivo reduzido e da capacidade explicativa limitada de suas formulações, somos exortados a reavaliar o estatuto canônico de um grupo bastante seleto de narrativas a propósito da vida moderna. Concomitantemente, ante o desafio de capturar um panorama social bem mais intricado e desconexo que o previsto, urge examinar os conflitos e as tensões em que se veem enredados os distintos preceitos ético-morais, referências cognitivas e parâmetros estéticos que coabitam a paisagem contemporânea. Por fim, atentos às suas posições assimétricas no tecido social, somos em igual medida convidados a ponderar acerca do potencial heurístico de proposições alternativas a respeito das gêneses e reconfigurações da modernidade.

Pois bem, conforme alguns analistas já tiveram oportunidade de sugerir, em meio a esforços efetuados com vistas à explanação da sociedade brasileira - leia-se, à elucidação de suas condições de possibilidade particulares e de seus padrões societários supostamente especiais -, obras de interpretação do país acabaram por oferecer insights valiosos à compreensão de fenômenos atinentes a um rol variado de contextos modernos (Bastos, 2011: 52-67; Lage, 2016: 45; Maia, 2011: 81-87; Ricupero, 2013: 529-530; Schwarz, 1998: 13; 1973: 159-160; Tavolaro, 2005; 2014: 654-656; 2020: 254-258) ${ }^{21}$. Como quero argumentar, à frente da tarefa de apreender uma condição alegadamente ímpar, formulações do pensamento brasileiro lançaram mão de imagens não convencionais da própria modernidade, consentâneas ao discernimento de aspectos subapreciados pelo cânone sociológico. Se é que se pode tomar tal proposta como um exercício de "desprovincianização" desse pensamento ${ }^{22}$, há ao menos dois fatores que me parecem garantir lastro ao empreendimento. Em primeiro lugar, retratos delineados em diversas obras de interpretação do país com frequência conferiram relevância à dimensão relacional dos processos e das transformações que concorreram para a formação nacional e seu ulterior ingresso na quadra moderna: malgrado a obsessão com os presumidos descompassos do Brasil vis-à-vis os chamados cenários modelares, nossos intérpretes conservaram-se atentos aos vínculos dessa experiência com um sem-número de itinerários, imprescindíveis à compreensão dos padrões de sociabilidade sedimentados no curso de sua história (Rocha, 2008; Feldman, 2009; Lage, 2016). A meu ver, há aqui afinidades importantes com as críticas ao teor internalista (autorreferente) de narrativas hegemônicas, em particular à sua inclinação para confinar a modernidade numa gama restrita de trajetórias históricas (Chakrabarty, 2000; Conrad, 2016). Levadas às últimas consequências, em um e outro casos, tais proposições apontam 
para as complementariedades entre contextos modelares e não modelares ${ }^{23}$ : no limite, trata-se de dizer que os diversos padrões de sociabilidade (as visões de mundo, os arranjos institucionais, as referências cognitivas e os parâmetros ético-morais e estéticos) coexistentes na paisagem moderna resultaram de uma infinidade de conexões e entrelaçamentos (culturais, econômicos, epistemológicos, políticos, militares etc.) em que estiveram envolvidas distintas partes do globo - coetâneas, ainda que assimetricamente posicionadas ${ }^{24}$. Por esse motivo, o conhecimento das múltiplas determinações de um segmento poderia oferecer sugestões para o entendimento do conjunto ${ }^{25}$.

O segundo fator a se considerar é que tal perspectiva relacional inscrita em obras do pensamento brasileiro também nos instiga a refletir a respeito do alcance heurístico dos padrões societários entrevistos no país. Ao invés de tomá-los como peculiares à vida nacional (porventura também pertinentes a outros contextos "tardios" e "marginais"), os aspectos anteriormente mencionados poderiam ser concebidos como parâmetros sociológicos alternativos, capazes de alargar os horizontes de cognição do imaginário da modernidade: refiro-me uma vez mais à justaposição e imprecisão funcional de domínios sociais diversos (Estado, mercado, sociedade civil, família, instituições culturais etc.); à persistência de concepções de mundo mágico-religiosas e de normas de conduta tradicionais no tecido social e na subjetividade dos indivíduos; à porosidade entre âmbitos domésticos e esferas públicas de convivência; e, por fim, à suscetibilidade da vida social às inconstâncias do mundo natural (Tavolaro, 2017: 125-128). Em suma, em vez de resíduos extemporâneos de uma ordem pré-moderna, tratar-se-ia de noções habilitadas a auxiliar a sociologia a apreender um escopo mais sortido de experiências e configurações sociais do presente. Também aqui, em virtude da condição relacional da modernidade, a análise de padrões divisados em seções específicas do conjunto lançaria sugestões à compreensão de aspectos distintivos do todo ${ }^{26}$.

Ao fim e ao cabo, essas ideias nos encorajam a reexaminar, sob nova luz, o sentimento de descompasso difuso nos retratos do Brasil contemplados neste artigo. É certo que ao imputar ao país uma condição tardia e reflexa, à primeira vista, as obras em tela parecem apenas atestar a valência epistemológica daquela concepção hegemônica: às decalagens, desacertos e incongruências da vida social brasileira se contraporia o tempo homogêneo, linear e progressivo de cenários modelares. Todavia, tão logo apreciados em diálogo com formulações críticas ao imaginário sociológico, esses mesmos retratos insinuam um registro analítico alternativo. Uma vez dissolvida a autossuficiência histórica das ditas sociedades "centrais" em favor de uma concepção relacional da experiência moderna (de acordo com a qual contextos modelares e não modelares seriam cooriginários e corresponsáveis pela modernidade);
23. Para escapar a dualismos dessa natureza, as sugestões lançadas por Carvalho Franco (1976 61-62) continuam auspiciosas: em lugar de tratá-las como "termos em oposição" atrelados "por uma relação de causalidade", mais apropriado seria conceber "colônia e metrópole" - ou, como prefiro aqui cifrar, contextos modelares e experiências nãomodelares - como partícipes do mesmo "sistema".

24. Para uma ênfase analítica nas conexões e entrelaçamentos societários implicados no surgimento da modernidade e em suas reconfigurações posteriores, ver Elias (1978), Subrahmanyan (1997) e Therborn (2003).

25. Em termos relacionais, seria inconcebível pensarse em trajetórias sociais exclusivas e autossubsistentes na modernidade; mutatis mutandis, seria descabido conceber-se experiências "modelares" desvinculadas de contextos "não modelares", e viceversa. Em última instancia, vale aqui o que François Dépelteau (2013: 180) propõe em sua abordagem relacional da vida 
social: "A não pode fazer aquilo que faz sem $B$, e vice-versa. [...] nada advém simplesmente de qualquer capacidade interna [...].

[...] todas essas capacidades e suas referidas ações acontecem sempre em relação a alguma outra coisa."

26. Nos termos de Schwarz (1987: 45),

"a má-formação brasileira, dita atrasada, manifesta a ordem da atualidade a mesmo título que o progresso dos países adiantados." Dito de outro modo, imagens do mundo e padrões de sociabilidade entrevistos no Brasil podem nos fazer compreender lógicas, códigos e regras de convivência observados também nos chamados cenários modelares. admitida a pertinácia hodierna de referências cognitivas e de padrões ético-morais e estéticos erigidos em circunstâncias e momentos históricos variados; e, por fim, assentida a coexistência contemporânea de uma pluralidade de conotações e ordenamentos do tempo (com suas lógicas, cadências, continuidades, interrupções, conflitos e subversões próprios), o arranjo temporal subjacente às interpretações do Brasil examinadas no artigo assume outro estatuto conceitual: em vez de exclusiva ao país e a contextos congêneres, tal concepção heterogênea, compósita e sinuosa do tempo parece melhor condizer com a densidade da trama social contemporânea e com as incongruências e assimetrias inerentes à(s) sua(s) temporalidade(s). Nesse, como em outros aspectos, as alardeadas assincronias brasileiras abrem caminhos auspiciosos para uma crítica epistemológica do imaginário da modernidade.

\section{Referências}

ALTHUSSER, Louis. The errors of classical economics: outline of a concept of historical time. In ALTHUSSER, Louis; BALIBAR, Étienne. Reading Capital, p. 91-118. London: NLB, 1970 [1965].

ANDERSON, Benedict. Imagines communities. London: Verso, 1991.

ANDRADE, Oswald de. Manifesto da Poesia Pau Brasil. In: . Manifesto Antropófago e outros textos, p. 19-28. São Paulo: Penguin Classics; Companhia das Letras, 2017a [1928].

ANDRADE, Oswald de. Manifesto Antropófago. In: Manifesto Antropófago e outros textos, p. 43-60. São Paulo: Penguin Classics; Companhia das Letras, 2017b [1928].

BASTOS, Elide R. A construção do debate sociológico no Brasil. Ideias - Revista do Instituto de Filosofia e Ciências Humanas da Unicamp, v. 1, p. 287-300, 2013.

BLOCH, Ernst. Nonsynchronism and the obligation to its dialectics. New German Critique, n. 11, p. 22-28, spring 1977.

BOMFIM, Manoel. A América Latina: males de origem. Rio de Janeiro: Topbooks, 1993 [1905].

BOTELHO, André; SCHWARCZ, Lília. Um enigma chamado Brasil: 29 intérpretes e um país. São Paulo: Companhia das Letras, 2009.

BRANDÃO, Gildo. Linhagens do pensamento político brasileiro. São Paulo: Aderaldo \& Rothschild Editores, 2007. 
CARDOSO, Fernando H. Pensadores que inventaram o Brasil. São Paulo: Companhia das Letras, 2013.

CARDOSO, Fernando H.; FALETTO, Enzo. Dependência e desenvolvimento na América Latina: ensaio de interpretação sociológica. Rio de Janeiro: Civilização Brasileira, 2004 [1969].

CARVALHO FRANCO, Maria Sylvia. As idéias estão no lugar. Cadernos de Debate, n. 1, p. 61-64. São Paulo: Brasiliense, 1976.

CHAKRABARTY, Dipesh. Provincializing Europe: postcolonial thought and historical difference. Princeton, NJ: Princeton University Press, 2000.

CHATTERJEE, Partha. La nación en tiempo heterogêneo y otros estúdios subalternos. Buenos Aires: Siglo XXI, 2008.

CONRAD, Sebastian. What is global history? Princeton, NJ: Princeton University Press, 2016.

COSTA, Sérgio. Desprovincializando a sociologia: a contribuição pós-colonial. Revista Brasileira de Ciências Sociais, v. 21, n. 60, p. 117-134, 2006.

COSTA PINTO, Luiz de A. Sociologia e desenvolvimento: temas e problemas de nosso tempo. Rio de Janeiro: Civilização Brasileira, 1973 [1962].

CUNHA, Euclides. Os Sertões. São Paulo: Ubu Editora, 2016 [1902].

DÉPELTEAU, François. What is the direction of the "relational turn"? In: POWELL, Christopher; DÉPELTEAU, François (Eds.). Conceptualizing relational sociology: ontological and theoretical issues, p. 163-185. New York: Palgrave Macmillan, 2013.

DURKHEIM, Émile. The division of labor in society. New York: The Freee Press, 1997 [1893].

DUSSEL, Enrique. Europa, modernidade e eurocentrismo. In: LANDER, Edgardo (Org.). A colonialidade do saber: eurocentrismo e ciências sociais, p. 55-70. Buenos Aires: Clacso, 2005.

EISENSTADT, Shmuel. Multiple modernities. Dædalus, v. 129, n. 1, p. 1-29, 2000.

ELIAS, Norbert. The problem of the "inevitability" of social development. In: What is sociology?, p. 158-174. London: Hutchinson \& Co Ltd, 1978.

FAORO, Raymundo. Os donos do poder: formação do patronato político brasileiro. São Paulo, Globo, 2001 [1958]. 
FELDMAN, Luiz. O Brasil no mundo e vice-versa: Estado em Casa-Grande \& Senzala, Sobrados e mucambos e Raízes do Brasil. Dissertação (Mestrado em Relações Internacionais) - Pontifícia Universidade Católica do Rio de Janeiro (PUC-Rio), 2009.

FERNANDES, Florestan. Sociedade de classes e subdesenvolvimento. São Paulo: Global Editora, 2008 [1968].

A revolução burguesa no Brasil. São Paulo, Globo, 2006 [1975].

FREYRE, Gilberto. Casa-Grande \& Senzala: introdução à história da sociedade patriarcal no Brasil. Rio de Janeiro: Record, 2000 [1933].

Sobrados e mucambos: história da sociedade patriarcal no Brasil. Rio de Janeiro: Record, 1996 [1936].

FURTADO, Celso. Formação econômica do Brasil. São Paulo: Companhia das Letras, 2009 [1959].

GIDDENS, Anthony. As conseqüências da modernidade. São Paulo: Editora Unesp, 1991.

GUERREIRO RAMOS, Alberto. A redução sociológica. Rio de Janeiro: Editora UFRJ, 1996 [1958].

GUMBRECHT, Hans. Nosso amplo presente. São Paulo: Editora Unesp, 2015. . Modernização dos sentidos. São Paulo: Editora 34, 1998.

HABERMAS, Jürgen. A consciência de época da modernidade e a sua necessidade de autocertificação. In: . O discurso filosófico da modernidade. Lisboa: Publicações Dom Quixote, 1990 [1985].

HALL, Stuart. Da diáspora: identidades e mediações culturais. Belo Horizonte: Editora UFMG, 2011 [2003].

HAROOTUNIAN, Harry. Remembering the historical present. Critical Inquiry, v. 33, p. 471-494, spring 2007.

HARVEY, David. The condition of postmodernity: an enquiry into the origins of cultural change. Cambridge, UK: Blackwell, 1995.

HOLLANDA, Sérgio Buarque de. Raízes do Brasil. Rio de Janeiro: José Olympio, 1936. KOSELLECK, Reinhart. Futuro passado: contribuição à semântica dos tempos históricos. Rio de Janeiro: Contraponto; Editora PUC-Rio, 2006. 
LAGE, Victor. Interpretations of Brazil, contemporary (de)formations. Tese (Doutorado em Relações Internacionais) - Pontifícia Universidade Católica do Rio de Janeiro (PUC-Rio), 2016.

LIMA, Nísia T. Um sertão chamado Brasil. São Paulo: Hucitec, 2013.

LYOTARD, Jean-François. A condição pós-moderna. Rio de Janeiro: José Olympio, 2013 [1979].

LUHMANN, N. The future cannot begin: temporal structures in modern society. Social Research, v. 43, n. 1, p. 130-152, 1976.

MAIA, João. Ao sul da teoria: a atualidade teórica do pensamento social brasileiro. Sociedade e Estado, v. 26, n. 2, p. 71-94, 2011.

MARX, Karl. Capital, v. 1. New York: Pinguin Classics, 1990 [1867].

A contribution to the Critique of Hegel's "philosophy of right". In:

Critique of Hegel's philosophy of right, p. 129-142. Cambridge, UK: Cambridge University Press, 1970 [1843-1844].

MORFINO, Vittorio. On non-contemporaneity: Marx, Bloch, Althusser. In: MORFINO, Vittorio; THOMAS, Peter D. (Eds.). The government of time: theories of plural temporality in the marxist tradition, p. 117-147. Chicago, II: Haymarket Books, 2018.

MORFINO, Vittorio; THOMAS, Peter D. Introduction: tempora multa. In (Eds.). The government of time: theories of plural temporality in the marxist tradition, p. 1-19. Chicago, II: Haymarket Books, 2018.

NABUCO, Joaquim. O abolicionismo. São Paulo: Publifolha, 2000 [1883].

PRADO JR., Caio. Formação do Brasil contemporâneo. São Paulo: Companhia das Letras, 2011 [1942].

PRADO, Paulo. Retrato do Brasil: ensaio sobre a tristeza brasileira. São Paulo: Companhia das Letras, 2012 [1928].

RICUPERO, Bernardo. O lugar das ideias: Roberto Schwarz e seus críticos. Sociologia \& Antropologia, v. 3, n. 6, p. 526-556, 2013.

ROCHA, João. O exílio como eixo: bem-sucedidos e desterrados - ou por uma edição crítica de Raízes do Brasil. In: MONTEIRO, Pedro; EUGÊNIO, João (Eds.). Sérgio Buarque de Holanda: perspectivas, p. 245-275. Campinas; Rio de Janeiro: Editora Unicamp; Editora Uerj, 2008. 
ROMERO, Silvio. Compêndio de história da literatura brasileira. Rio de Janeiro: Imago Editora, 2001 [1906].

História da literatura brasileira. Tomo Primeiro. Rio de Janeiro: Livraria José Olympio, 1949 [1888].

ROSA, Harmut. Social acceleration: a new theory of modernity. New York: Columbia University Press, 2013.

SCHMIDT, Volker. Conceptualizing global modernity: a tentative sketch. Working Papers Series, n. 191. Department of Sociology, National University of Singapore, 2012. Disponível em: <https://ap4.fas.nus.edu.sg/fass/socvhs/research/Conceptualizing\%20Global\%20Modernity.pdf>. Acessado em: 23 Dez. 2019.

SCHWARZ, Roberto. Um mestre na periferia do capitalismo: Machado de Assis. São Paulo: Duas Cidades, 1998.

Que horas são? Ensaios. São Paulo: Companhia das Letras,1987. Ideias fora do lugar. Estudos Cebrap, v. 5, p. 151-161, 1973.

SIMMEL, Georg. The metropolis and mental life. In: LEVINE, Donald (Ed.). Georg Simmel: on individuality and social forms. Chicago, II: The University of Chicago Press, 1971.

SUBRAHMANYAM, Sanjay. Connected histories: notes towards a reconfiguration of early modern Eurasia. Modern Asian Studies, v. 31, n. 3, p. 735-762, 1997.

TAVOLARO, Sergio B. F. Stasis, motion and acceleration: the senses and connotations of time in Raízes do Brazil and Sobrados and Mucambos (1936). Sociologia e Antropologia. v. 10, n. 1, p. 243-266, 2020.

Retratos não-modelares da modernidade: hegemonia e contra-hegemonia no pensamento brasileiro. Civitas, v. 17, n. 3, p. 115-141, 2017.

A tese da singularidade brasileira revisitada: desafios teóricos contemporâneos. Dados - Revista de Ciências Sociais, v. 57, n. 3, p. 633-673, 2014.

À sombra do mato virgem...: natureza e modernidade em uma abordagem sociológica brasileira. Ambiente e Sociedade, v. 11, n. 2, p. 273-287, 2008.

Existe uma modernidade brasileira? Reflexões em torno de um dilema sociológico brasileiro. Revista Brasileira de Ciências Sociais, v. 20, n. 59, p. 5-22, 2005. 
TORRES, Alberto. O problema nacional: introdução a um programa de organização nacional. Brasília: Companhia Editora Nacional; MEC, 1978 [1914].

VIANNA, Oliveira. Evolução do povo brasileiro. Rio de Janeiro: José Olympio, 1956 [1922].

VILLAS-BÔAS, Glaucia. Casa grande e terra grande, sertões e senzala: a sedução das origens. In: KOSMINSKY, Ethel; LÉPINE, Claude; PEIXOTO, Fernanda (Orgs.). Gilberto Freyre em quatro tempos, p. 115-134. Bauru, SP: Edusc, 2003.

VILLAS-BÔAS, Glaucia. Mudança provocada. Passado e futuro no pensamento sociológico brasileiro. Rio de Janeiro: Editora FGV, 2006.

WEBER, Max. The protestant ethic and the spirit of capitalism. Los Angeles, CA: Roxbury Publishing Company, 2002 [1905].

ZERUBAVEL, Eviatar. The standardization of time: a sociohistorical perspective. American Journal of Sociology, v. 88, n. 1, p. 1-23, 1982.

Outras fontes:

Manifesto Nhegaçu Verde Amarelo (1929) [mimeo]. 
